\title{
Crezcamos felices: Manual sobre prevención de la violencia para mentoras del programa Abriendo Oportunidades
}

Population Council

Follow this and additional works at: https://knowledgecommons.popcouncil.org/departments_sbsr-pgy How does access to this work benefit you? Let us know!

\section{Recommended Citation}

"Crezcamos felices: Manual sobre prevención de la violencia para mentoras del programa Abriendo Oportunidades." Ciudad de Guatemala: Population Council, 2021. 


\section{POPULATION \\ Ideas. Evidence. Impact.}

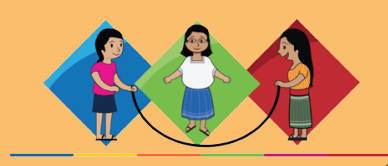

$\overline{\text { Abriendo Oportunidades }}{ }^{\circ}$

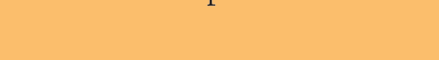


El Population Council enfrenta problemas críticos de salud y desarrollo, desde detener la propagación del VIH hasta mejorar la salud sexual reproductiva y garantizar que los jóvenes lleven una vida plena y productiva. A través de la investigación biomédica, de ciencias sociales y de salud pública en 50 países, trabajamos con nuestros socios para ofrecer soluciones que conduzcan a políticas, programas y tecnologías más efectivas que mejoren vidas en todo el mundo. Establecido en 1952 y con sede en Nueva York, el Council es una organización no gubernamental, sin fines de lucro, gobernada por una junta internacional.

\section{Population Council Guatemala}

19 avenida 0-35 Zona 15, Vista Hermosa 2,

Ciudad de Guatemala, 01015 Guatemala

Tel: +502 2369-0292

popcouncil.org

Texto, diseño y diagramación:

Luis Méndez Salinas y Carmen Lucía Alvarado

Ilustraciones:

Paula Gramajo, Mario Valdez y Leke García

Ciudad de Guatemala, Population Council

(C) 2021 The Population Council, Inc.

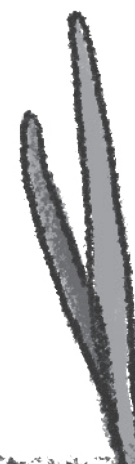




\section{Crezcamos felices}

\section{Manual sobre prevención de la violencia para mentoras del programa Abriendo Oportunidades ${ }^{\circledR}$}

Estamos a punto de iniciar un camino de aprendizaje y compañía que sin duda nos cambiará la vida. Como mentora, tienes una gran responsabilidad, que vendrá acompañada de muchas alegrías, desafíos y retos.

Durante ocho sesiones, guiarás a un grupo de niñas y compartirás con ellas tus conocimientos y tus experiencias personales. Así podrán crecer juntas y saberse parte de una comunidad basada en la confianza, el respeto y el cariño.

Hemos preparado esta guía con la intención de ofrecerte herramientas que te sean útiles para generar ideas, reflexiones y preguntas en cada una de las niñas que se integre a tu grupo de Abriendo Oportunidades ${ }^{\circledR}$.

Las sesiones de este proceso tienen una estructura muy sencilla, que tú podrás modificar usando tu creatividad y acomodando los temas y sugerencias a las condiciones del grupo y el lugar con que trabajas. No hay límites para que tú puedas crear experiencias, dinámicas y contenidos nuevos, y lo que te presentamos aquí es una base sobre la que podrás construir lo que consideres más adecuado.

Nos interesa mucho que en cada sesión, las niñas tengan cuatro experiencias principales:

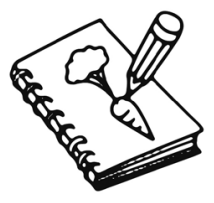

- Que aprendan herramientas útiles para enfrentar los retos de su día a día.

- Que sientan emociones nuevas a través del contacto con el arte.

- Que puedan expresarse libremente y compartir sus experiencias.

- Que generen juntas un espacio colectivo de aprendizaje y confianza, una red de apoyo y amistad que vaya más allá de estas ocho sesiones.

Por eso, en este manual encontrarás una serie de indicaciones sencillas para desarrollar cada sesión a partir de cuatro momentos:

Aprendamos juntas: compartirás con las niñas un tema, y tratarás

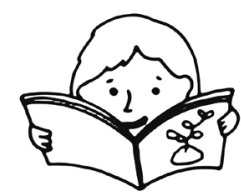
de explicarles de manera clara los contenidos relacionados. Para ello, te proporcionaremos información de base, que podrás complementar fácilmente investigando por tu cuenta. Recuerda que $A O$ te acompañará en el proceso y que junto a tus compañeras mentoras podrás compartir conocimientos que sean útiles para todas. 
Escuchar es sentir: La vida está llena de emociones y el arte es una forma estupenda de poder explorarlas plenamente. Por eso, queremos $\div$ (0) que en cada sesión todas tengan contacto con alguna canción, algún video, alguna pieza que las haga pensar y sentir, más allá de los aprendizajes formales. En esta ocasión te compartiremos canciones y videos que de alguna manera se relacionan con el tema principal de cada sesión. La idea es que puedan escucharla, sentirla y platicar sobre ella. La música y las imágenes nos ayudarán a conectar emocionalmente con los temas que trataremos durante este camino.

Compartamos nuestras experiencias: a partir del tema correspondiente a cada sesión, es importante que estimules un espacio de

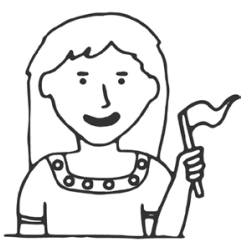
reflexión y participación de todas, para que cada una pueda expresarse libremente y compartir ideas con el grupo. La experiencia personal es clave en este proceso de aprendizaje, y las niñas y tú podrán aprender mucho escuchándose unas a otras. Cuando tú hables, las niñas conectarán con tu experiencia y te tomarán como referencia para resolver cuestiones de sus propias vidas. Por eso, el diálogo es fundamental para crear lazos en tu comunidad de $\mathrm{AO}$.

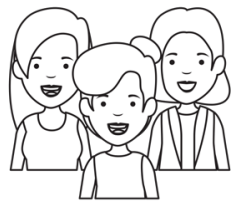

Hagamos algo juntas: a partir de ciertas dinámicas buscaremos que las sesiones sean divertidas, y que las niñas la pasen bien mientras aprenden. Aquí te propondremos algunas opciones, que tú podrás modificar con libertad, tratando de que sean adecuadas para las niñas.

Adicionalmente, compartiremos contigo algunos recursos (documentos, enlaces, videos, etc.) que te ayudarán a reforzar tus conocimientos y a compartir de manera apropiada los contenidos con las niñas de tu grupo. El internet puede serte muy útil para completar esos recursos y para investigar por tu propia cuenta.

Empecemos, pues, nuestro camino. 


\section{Primera sesión}

No estamos solas

Hoy empezaremos un camino de aprendizaje que nos alegrará durante ocho semanas. Desde el inicio, es importante que estimules la comunicación abierta y la confianza entre todas. Por eso, cuando las niñas vayan llegando al lugar de la reunión, salúdalas cariñosamente y platica con ellas.

\section{Compartamos nuestras experiencias}

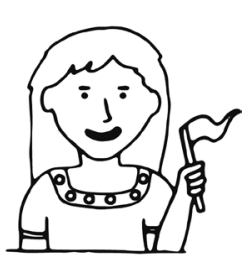

Cuando todas hayan llegado, dales la bienvenida y comparte con ellas tu entusiasmo por el proceso que está a punto de empezar. Pídeles que se presenten y que les cuenten a las demás por qué están aquí, cómo se enteraron del grupo de $\mathrm{AO}$ y qué esperan de participar en este espacio. El diálogo será nuestra principal herramienta para conocernos unas a otras.

\section{Aprendamos juntas}

Partamos de nuestra propia experiencia.

Pregúntale a las niñas si alguna vez alguien les ha dicho que es muy raro que las mujeres estén juntas, que las rivalidades que surgen entre ellas hacen imposible cualquier amistad.

\section{¿Les ha sucedido?}

Estimula la participación de ellas, permite que te cuenten sus experiencias.

Al terminar, comparte con ellas esta reflexión:

La sociedad en que vivimos muchas veces coloca en una posición de

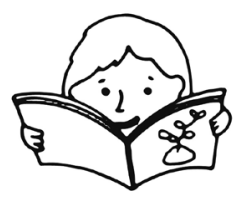
desigualdad de oportunidades a las mujeres. Para poder salir adelante en un contexto que muchas veces nos discrimina y nos impide el bienestar, es necesario que nos apoyemos unas a otras para poder avanzar juntas. La amistad es un aspecto clave de la vida, y la solidaridad es fundamental para que todas podamos estar bien.

Si vemos a alguien que está pasando por un momento difícil, ¿̇qué debemos hacer?

Explora con las niñas las posibles respuestas. 


\section{Hagamos algo juntas}

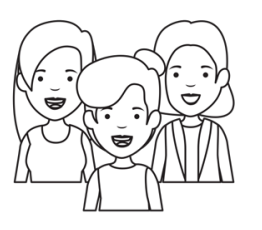

Haremos una actividad sencilla para empezar a conocernos mejor. Para ella necesitarás crayones y hojas de papel, que repartirás entre las niñas para que cada una pueda hacer un dibujo.

Comparte con ellas las siguientes instrucciones:

1. Cada una deberá pensar en un ser vivo que le guste mucho y con el que se sienta identificada. Puede ser un animal, una planta, o un lugar de la naturaleza.

2. Cuando cada una lo haya pensado bien, deberá dibujarlo en la hoja que les entregues.

3. Después de un tiempo prudencial, pídele a las niñas que compartan con sus compañeras sus dibujos, y que traten de explicar por qué se sienten relacionadas o atraídas a lo que dibujaron.

Esto nos ayudará a conocer la personalidad de nuestras compañeras, sus gustos y sus intereses.

\section{Escuchar es sentir}

Hoy conoceremos a una cantante que nació en la ciudad de Guatemala.

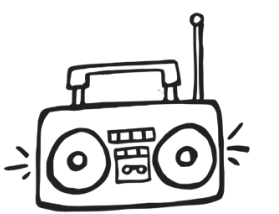
Se llama Dominique Hunziker y tiene 22 años. Escribió esta canción que ahora escucharemos. Lleva por título "Nieta del alba".

Encontrarás la canción en el siguiente enlace:

https://www.youtube.com/watch?v=cypAJ4S02r4

Luego de escucharla, pregúntale a las niñas:

- ¿QQué les pareció la canción?

- ¿QQué frase les llamó la atención?

Hay una pregunta importante que nos deja esta canción a cada una:

- ¿̇Para qué nacimos?

Tratemos de responderla pensando en lo que nos gusta, en lo que queremos hacer con nuestra vida.

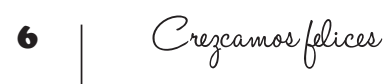




\section{Para la próxima sesión}

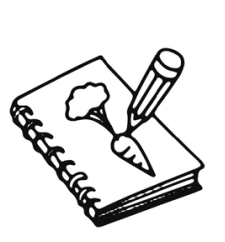

Pídele a las niñas que escojan un objeto personal con el que se sientan muy identificadas, y que lo traigan a la próxima sesión. Puede ser cualquier cosa, un objeto que tenga una historia y un sentido especial para ellas. Recomiéndales que sea pequeño y portátil, pues lo utilizaremos durante la próxima sesión. Encárgales mucho que no lo olviden.

Además, tú deberás conseguir un canasto ancho, en donde quepan los objetos que las niñas llevarán. Calcula bien las dimensiones para que sea lo suficientemente grande. 


\section{Segunda sesión}

\section{Nuestro cuerpo cambia}

Sigamos creciendo felices en esta segunda sesión. Recibe a las niñas con una sonrisa y pregúntales qué tal estuvo su semana. Cuéntales cómo te fue a ti. La plática informal antes del inicio de la sesión les ayudará a tender lazos más fuertes entre ustedes.

\section{Hagamos algo juntas}

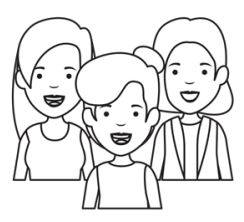

Cuando todas se hayan reunido, dales la bienvenida y cuéntales que hoy empezaremos con una actividad muy significativa. Pídeles que tengan a mano el objeto especial que les pediste la semana pasada. Vayan a un lugar cómodo, donde puedan estar reunidas, y coloca en medio de todas el canasto que conseguiste.

Cuéntales que ese canasto representará la comunidad que juntas formamos. Pídele a cada una que vaya colocando con cuidado su objeto dentro del canasto y que lo deje ahí.

Cuando todas terminen, párense alrededor del canasto y obsérvenlo. Pongan atención en todos esos objetos que representan a cada una. No sabemos cuál es su historia, pero sabemos que si están ahí son importantes para nuestras compañeras.

Cada objeto nos representa a nosotras, y la canasta llena representa la comunidad que formamos. Somos diversas, pero formamos parte de un todo. Reflexionen juntas sobre esto, y tengan el canasto a la vista durante toda la sesión.

\section{Aprendamos juntas}

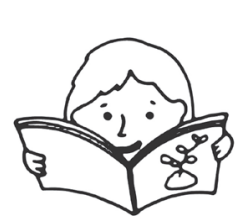

Para esta sesión es importante que hablemos de dos temas muy relacionados. Primero, hablaremos de nuestros cuerpos, y de los cambios que experimentamos a lo largo de nuestras vidas. $Y$ luego, veremos cómo esos cambios tienen mucho que ver con los cambios y los ciclos de la luna.

Para desarrollar mejor estos contenidos, tú como mentora deberás investigar de acuerdo a las edades de las niñas que integran tu grupo.

Nosotras te facilitaremos un documento que te será muy útil, y que deberás estudiar antes de esta sesión. Se llama "Así me habla la luna: un libro sobre nuestro ciclo menstrual", escrito por Cecilia Pérez Juárez y Andrea Aguilar Ferro. 
Al leerlo podrás encontrar formas de compartir con las niñas todos estos contenidos.

\section{Escuchar es sentir}

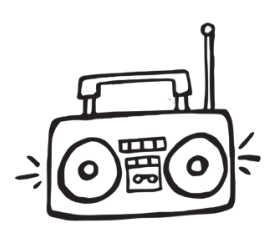

Además del ritmo y la melodía, las canciones comunican ideas poderosas. Te ponemos a continuación dos canciones que tienen que ver con la luna y el cuerpo, puedes escoger cualquiera de las dos, o incluso pueden poner las dos para tener una idea más amplia de la relación que tiene la luna sobre nuestro cuerpo y sobre nuestros ciclos.

La primera canción se llama "Luna compañera" del grupo Laia y está en este enlace:

https://www.youtube.com/watch?v=yyVAafSywYA

La segunda es de Rebeca Lane, se llama "Mujer lunar" y la encontrarás en el siguiente enlace:

https://www.youtube.com/watch?v=XO7GZmwQCb8

Al terminar, discutan qué les parecieron las canciones. Trata de que la mayor parte de las niñas opine con libertad.

\section{Compartamos nuestras experiencias}

Estamos a punto de terminar nuestra segunda sesión, y en medio de nosotras hay un canasto que guarda objetos que significan mucho para cada una. Como última actividad del día, pídele a las niñas que se reúnan alrededor del canasto y que vayan tomando lentamente sus respectivos objetos. Al hacerlo, deberán contar brevemente por qué seleccionaron ese objeto para que las acompañara a la sesión de hoy. Diles que no tengan pena de contar la historia que las une a su objeto. Cada una irá interviniendo según quiera, hasta que el canasto se vacíe por completo. Al terminar, agradécele a las niñas por compartir sus historias, que ahora también son historias de la comunidad que conformamos.

Despídelas con entusiasmo y diles que no falten la próxima semana, pues aprenderán muchas cosas juntas. 


\section{Tercera sesión}

\section{Nosotras en el entorno}

Saluda a las niñas, pregúntales cosas, cuéntales tus experiencias de la semana. Tu cercanía será muy útil para que se mantengan dentro de este proceso de aprendizaje colectivo.

\section{Hagamos algo juntas}

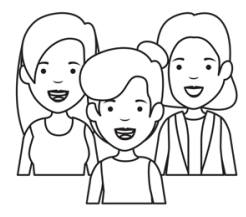

En esta ocasión, haremos un mapa de nuestra comunidad e intentaremos dibujar en él nuestras emociones. ¿̇ué nos hace sentir el espacio que habitamos todos los días? ¿Nos da confianza, nos alegra, nos sentimos cómodas?

Comparte con las niñas las siguientes instrucciones:

1. En una hoja de papel (o en un papelógrafo o cartulina, lo que les resulte más fácil) cada una deberá dibujar un mapa de su comunidad. En él identificarán el lugar donde viven, las calles, los parques, los espacios públicos, los lugares naturales que les gustan... todo lo que les ayude a reconocer el espacio que ven todos los días.

2. Después de terminar el dibujo pídeles que marquen con estos colores los lugares que las hagan sentir estas emociones específicas:

- Amarillo: lugares donde han vivido momentos felices.

- Rojo: lugares donde se hayan sentido tristes.

- Azul: lugares donde les guste estar.

La memoria y las emociones están fuertemente ligadas al espacio en que habitamos, y por eso es importante saber cómo nos sentimos en él.

3. Al terminar, pídeles que se reúnan en parejas o tríos, y que compartan con sus compañeras sus dibujos y los lugares que marcaron.

\section{Compartamos nuestras experiencias}

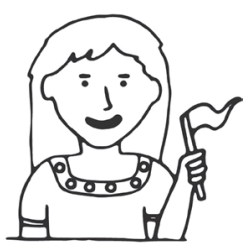

Después de un tiempo prudencial, reúnanse todas y platiquen sobre la experiencia que acaban de tener. ¿Cómo ven ahora su comunidad, su territorio, su espacio? ¿Cómo se combinan las emociones de todas en los lugares que comparten?

\section{Aprendamos juntas}

Hoy hablaremos de dos tipos de violencia que suelen pasar desapercibido en nuestro entorno social. Cuando estos tipos de violencia se producen, lo vemos como algo normal. 
Pero la violencia, en cualquiera de sus formas, no es normal. Por eso, debemos ser capaces de identificarla para poder detenerla en caso se presente.

Explícale a las niñas el concepto de violencia estructural.

La violencia estructural se produce cuando enfrentamos situaciones en las que no podemos satisfacer una necesidad básica a causa de

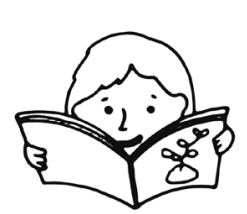
procesos históricos y sociales relacionados con la sociedad en que vivimos. Cuando el sistema que nos rodea nos niega la supervivencia, el bienestar, la identidad o la libertad, estamos siendo afectadas por la violencia estructural, aunque nadie nos haga un daño directo. La desigualdad de oportunidades entre niñas y niños es un ejemplo muy cercano de violencia estructural. ¿Cómo podemos enfrentar este tipo de violencia?

Pensando en cómo incidir en las formas en que se organiza nuestra sociedad misma. Tratando de cambiar las reglas de un juego que es injusto.

Explícale a las niñas el concepto de violencia económica, que se relaciona estrechamente con la violencia estructural.

Muchas veces, la violencia estructural se manifiesta como violencia económica. ¿Qué es la violencia económica? Es cuando alguien más -por lo general un hombre que provee el dinero para el mantenimiento de la casa-controla todos los bienes de una familia. También se produce violencia económica cuando alguien más se apropia del dinero que una mujer ganó con su trabajo. O cuando el jefe de la familia no deja que la mujer trabaje y genere sus propios ingresos, a fin de que no descuide las tareas del hogar.

¿Qué podemos hacer para enfrentar ambos tipos de violencia?

Trata de pensar en experiencias concretas que conozcas, y extrae de ellas algún aprendizaje que puedas compartir con las niñas. Dos conceptos te pueden ayudar: la autonomía y la soberanía.

Autonomía: la autonomía es un concepto que define la capacidad de producir, pensar y realizar actividades sin necesidad de depender de una estructura mayor. Por ejemplo, cuando producimos nuestro propio dinero con la venta de lo que sembramos en nuestro huerto, estamos siendo autónomas.

Soberanía: escapar de un régimen y definir a partir de eso la libertad de una colectividad. Un ejemplo claro es la forma en que los países latinoamericanos decidieron desligarse del poder político de España. 
¿Conoces mujeres autónomas, capaces de tomar sus propias decisiones, enfrentar los retos de su vida y buscar su bienestar, sin necesidad de depender de nadie? Comparte esos conocimientos con las niñas, y pregúntales por su opinión.

\section{Escuchar es sentir}

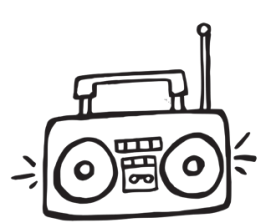

Esta canción es alegre y tiene que ver con nosotros como pueblos parte del continente americano. Es de una banda colombiana llamada Aterciopelados, liderada por una cantante extraordinaria. Su nombre es Andrea Echeverri, y hoy la escucharemos cantar "La semilla nativa". Bailen, escuchen, sientan la música.

Encontrarás la canción en el siguiente enlace:

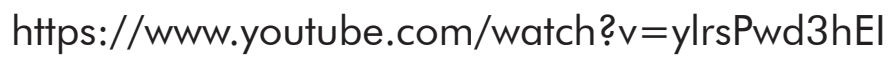

Repasa con las niñas la letra de la canción, y piensen juntas cómo se relaciona con su entorno, con su contexto, con las cosas que ven todos los días.

\section{Para la siguiente sesión}

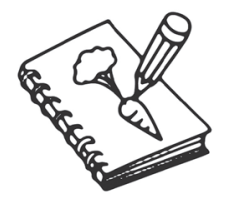

Trae uno de tus huipiles favoritos. Lo utilizaremos para graficar un ejemplo en la próxima sesión. Es importante que no lo olvides. 


\section{Cuarta sesión}

\section{No queremos tener miedo}

Estamos a la mitad de esta serie de sesiones. ¿̇Cómo sientes que ha avanzado el proceso? ¿Te sientes cómoda con tu grupo de AO? Analiza, piensa y comparte con las niñas. Pídeles a ellas que te den su opinión.

\section{Compartamos nuestras experiencias}

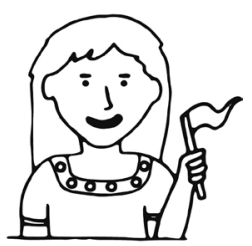

Hoy hablaremos sobre el miedo. Debes saber que el miedo se define como una sensación de angustia por un riesgo real o imaginario. Se parece mucho a la desconfianza y nos lleva a creer que algo malo puede pasarnos.

El miedo es algo que está presente en la vida de todas las personas, en un momento o en otro. Por eso, debemos conocerlo, reflexionarlo, hablarlo y evitar que nos paralice y nos haga daño.

Pregúntale a las niñas qué piensan del miedo.

- íLo han sentido?

- ¿Por qué?

- ¿̇En qué situaciones?

- ¿Qué han hecho para enfrentarlo?

Diles que la experiencia de cada una puede ayudar a sus compañeras cuando se encuentren en alguna situación similar. Por eso es importante que tú como mentora pienses en el miedo y guíes la conversación a través de la experiencia. El miedo se puede vencer. Lo vencemos a cada momento. ¿̇Cómo lo hacemos? Son preguntas importantes que podremos responder a partir de la conversación abierta.

También muchas veces el miedo está provocado por algo concreto. Así que si percibes que las niñas tienen miedo de algo objetivo, trata de escucharlas, que lo hablen contigo para ver que vías existen para solucionar su situación.

\section{Aprendamos juntas}

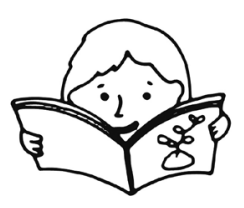

Para los contenidos de esta sesión utilizaremos las definiciones que nos ofrece el marco legal vigente de Guatemala. Como mentora, $\dot{2}$ conoces el Decreto número 22-2008, Ley contra el femicidio y otras formas de violencia contra la mujer? Esta es una herramienta legal muy 
importante para hacer valer nuestros derechos, y puedes encontrarla fácilmente en internet. Aquí te compartimos un enlace:

https://www.oas.org/dil/esp/ley_contra_el_femicidio_y_otras_formas_de_violencia_ contra_la_mujer_guatemala.pdf

Esta ley define los diversos tipos de violencia que se pueden ejercer contra las mujeres, y conocer estas formas de violencia nos ayudarán a identificarlas en nuestras propias vidas o en las vidas de las mujeres y niñas que tenemos cerca.

Hoy hablaremos de estos dos tipos de violencia: la física y la psicológica.

De acuerdo con la ley, la violencia física comprende "acciones de agresión en las que se utiliza la fuerza corporal directa o por medio de cualquier objeto, arma o sustancia con la que se causa daño, sufrimiento físico, lesiones o enfermedad a una mujer".

En cambio, la violencia psicológica o emocional implica "acciones que pueden producir daño o sufrimiento, psicológico o emocional a una mujer, a sus hijas o a sus hijos, así como las acciones, amenazas o violencia contra las hijas, los hijos $u$ otros familiares con el objeto de intimidarla, menoscabar su autoestima o controlarla, la que sometida a ese clima emocional puede sufrir un progresivo debilitamiento psicológico con cuadros depresivos".

Reflexiona con ellas sobre ambas definiciones, y trata de explorar su percepción respecto a estos tipos de violencia. ¿Las conocen? ¿́Logran identificarlas en la vida que las rodea?

\section{Hagamos algo juntas}

Es momento de sacar el huipil que trajiste. Colócalo sobre una mesa,

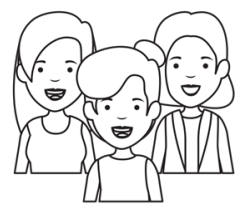
- una superficie alrededor de la que puedan colocarse las niñas cómodamente.

Diles que con ese huipil podremos ejemplificar un concepto complejo de nuestras propias personas.

Después de extenderlo, pídeles a las niñas que lo describan, que enumeren los colores y las formas que ven. Pregúntales qué se necesitó para producir este huipil. Después de que ellas den opciones, explícales que para realizar este tejido se tuvieron que juntar estos tres elementos:

1. Hilo, que es la materia prima que lo conforma.

2. La mano que lo tejió.

3. La idea de la tejedora. 
Cada una de nosotras, como personas integrales que somos, nos parecemos un poco a ese huipil. La gente nos podrá describir por lo que ve, por lo que conoce de nosotras. Pero somos mucho más que eso. Además de nuestro cuerpo, tenemos nuestra mente y nuestras emociones. Todo eso reunido, nos hace únicas. Como único es el huipil que está frente a nosotras.

\section{Escuchar es sentir}

Hay canciones que surgen de experiencias dolorosas, y que nos $\div$ (0) hacen pensar en personas que no conocemos. Hoy escucharemos la "Canción sin miedo", un canto de protesta por la violencia que muchas mujeres sufren en su vida. La compuso Vivir Quintana, pero una niña de Quetzaltenango llamada Dulce Zapata la adaptó para el contexto guatemalteco.

Escuchémosla juntas, y pensemos en todas esas mujeres, en todas esas niñas que han atravesado experiencias difíciles en su vida. Acompañémoslas, sintámonos con ellas.

Encontrarás la canción en el siguiente enlace:

https://www.facebook.com/labocinaguatemala.gt/videos/333197581318534

Después de escucharla, platiquen sobre lo que les hizo sentir. Déjales claro que canciones así nos tienen que transmitir fuerza. El hecho de cantarla todas juntas, de unir las voces, nos hace sentir que no estamos solas, y que siempre tendremos amigas con las que podemos contar. 


\title{
Quinta sesión
}

\author{
La decisión es nuestra
}

\section{Aprendamos juntas}

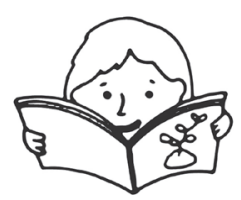

De acuerdo a la ley que conocimos en la sesión anterior (Decreto número 22-2008, Ley contra el femicidio y otras formas de violencia contra la mujer), la violencia sexual se define como cualquier acción de violencia física o psicológica cuya finalidad es vulnerar la libertad y seguridad sexual de la mujer, incluyendo la humillación sexual, la prostitución forzada y la prohibición a hacer uso a métodos de planificación familiar, tanto naturales como artificiales, o a adoptar medidas de protección contra enfermedades de transmisión sexual.

Pregúntale a las niñas si han visto a alguien cercano sufrir este tipo de violencia, y a partir de eso platiquen sobre los posibles motivos de que esta circunstancia exista.

¿Cómo podemos prevenir este tipo de violencia, que afecta a millones de mujeres en el mundo diariamente? Trata de pensar con ellas en las estrategias cotidianas que, desde nuestro entorno, podemos llevar a cabo para no enfrentar estas formas de violencia.

\section{Escuchar es sentir}

Pregúntale a las niñas si han escuchado antes la leyenda de "La

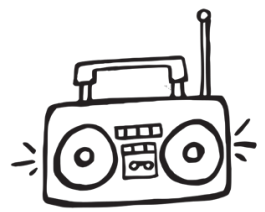
Siguanaba". Si no lo han hecho, puedes buscar en internet alguna referencia y compartirla con ellas. Cuéntales que hoy escucharemos una canción basada en esa leyenda, pero que nos enseñará algo que no sabíamos antes. La hizo una cantante de Comalapa, que se llama Sara Curruchich. Escuchémosla con atención.

Encontrarás la canción en el siguiente enlace:

https://www.youtube.com/watch?v=TtcuGxmWczU

\section{Compartamos nuestras experiencias}

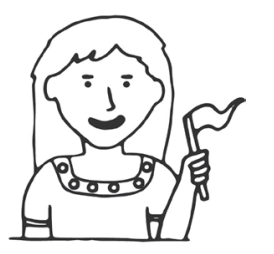

Respondamos juntas a esta pregunta:

¿Qué mensaje nos deja la canción? 


\section{Hagamos algo juntas}

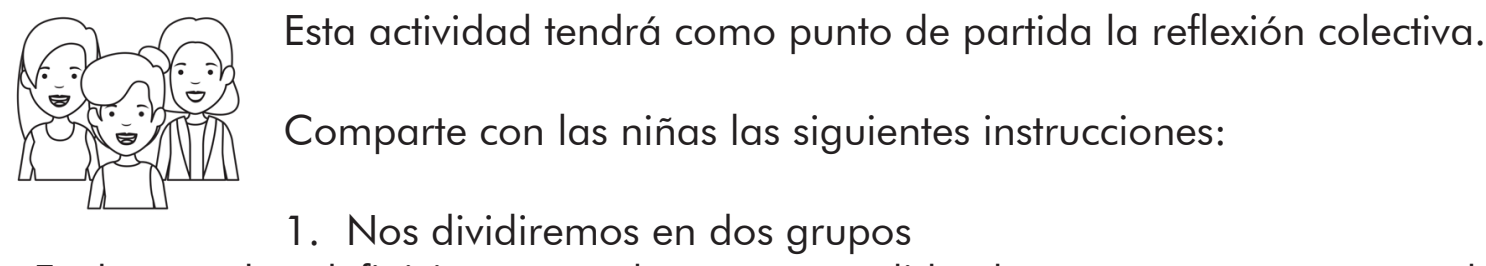

2. En base a las definiciones que hemos aprendido durante estas semanas sobre las formas más comunes de violencia contra las mujeres, cada grupo identificará un caso concreto de violencia contra las mujeres.

3. Luego de identificar el caso, organizaremos una dramatización que cuente esa historia de violencia. En la misma dramatización, deberán imaginar estrategias para evitar esa situación de violencia.

4. Al terminar, cada grupo dramatizará frente al otro su caso. Entre todas podrán discutir si las estrategias para enfrentar la violencia fueron efectivas, y aportar nuevas soluciones para enfrentar la violencia en nuestros propios contextos.

\section{Para la siguiente sesión}

Realizaremos una actividad en la que necesitaremos que cada niña traiga una mazorca de maíz. Si no pueden conseguirla, quizá tú como mentora podrás conseguir en algún lugar cercano una mazorca para

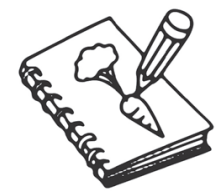
cada niña. Es importante que todas tengan una disponible para las actividades de la próxima sesión. 


\section{Sexta sesión}

\section{Somos parte de una red}

\section{Aprendamos juntas}

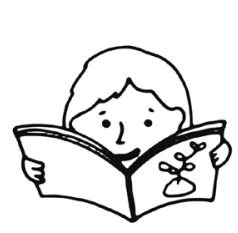

Si algo ha quedado claro en estas sesiones de nuestro grupo, es que no estamos solas. Siempre somos parte de una red, de una sociedad que pone retos, obstáculos y también oportunidades en nuestro camino. La solidaridad, la empatía, la amistad y el apoyo mutuo son fundamentales para que todas estemos bien.

Pero no solo este grupo de $A O$ es una red. Todo lo que nos rodea puede ayudarnos a vivir bien y a tener una vida libre de violencia. Ejemplo de ello son las diversas instituciones públicas y de la sociedad civil que pueden apoyarnos en cualquier caso. ¿̇Conocen algunas de esas instituciones?

Hoy platicaremos del trabajo que algunas realizan en nuestro departamento.

Para esta parte, debes investigar qué instituciones trabajan directamente con las mujeres cerca de tu comunidad. Como base, te mencionamos las siguientes:

\section{A nivel nacional:}

- Asociación de Mujeres Tierra Viva

- Centro de Acción Legal para Derechos Humanos (CALDH)

- Defensoría de la Mujer Indígena (DEMI)

- Procuraduría de los Derechos Humanos (PDH)

\section{A nivel departamental:}

- Consejo de Mujeres Mayas

- Fundación de Mujeres Mayas del Norte (FUNMAYAN)

- Fundación para el Desarrollo y Educación de la Mujer Indígena Talita Kumi

- Oficina Municipal de Mujeres - Alta Verapaz

En internet podrás encontrar detalles sobre el trabajo que cada iniciativa e institución realizan, y eso te será útil para compartirlo con las niñas.

Además, es importante que reflexionen juntas sobre el papel que las redes comunitarias de apoyo pueden jugar en nuestra realidad inmediata. Para ello, es importante diagnosticar cómo son las relaciones entre las personas que integran nuestra comunidad. 
Algo que es imprescindible para reducir el riesgo de que suframos cualquier tipo de violencia es establecer relaciones sanas, amistosas y solidarias con los hombres y mujeres que viven a nuestro alrededor.

¿Qué podemos hacer para que estas relaciones basadas en el respeto mutuo y la confianza se multipliquen en nuestra comunidad?

\section{Escuchar es sentir}

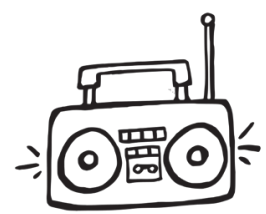

¿Recuerdan a nuestra amiga Sara Curruchich? La semana pasada escuchamos una canción suya, y hoy conoceremos otra. Esta vez, Sara nos habla de las comunidades que habitamos, de la red que formamos con

la gente que se encuentra a nuestro alrededor. Escuchemos atentamente y bailemos al ritmo de esta canción que se llama "Somos".

Encontrarás la canción en el siguiente enlace:

https://www.youtube.com/watch?v=PSM7LnynZjU

Discutamos: ¿̇uál es el mensaje que Sara nos quiere transmitir con esta canción?

\section{Hagamos algo juntas}

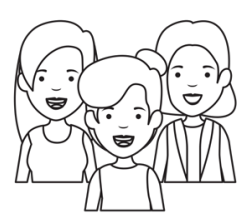

Ha llegado la hora de utilizar la mazorca que cada una de las niñas ha traído. En esta actividad aprenderemos a ver nuestra comunidad como una mazorca: cada uno de los granos del maíz representa a un individuo. ¿ेerdad que nunca vienen solos? ¿̇erdad que para existir necesitan de los demás? Platica con las niñas de este símbolo.

Luego, comparte con ellas las siguientes instrucciones:

1. Nos dividiremos en grupos de 4 o 5 participantes.

2. Cada grupo formará un círculo y cada una de nosotras irá compartiendo con las compañeras una historia sobre las personas buenas de nuestra comunidad. Podremos hablar de amigas, amigos y líderes que han hecho posibles cambios positivos en nuestras vidas. Mientras hablamos, iremos desgranando nuestra mazorca, y se entre nosotras se irá formando un montoncito de granos de maíz, que todas iremos reuniendo al centro del grupo.

3. Al terminar, veremos que nuestros maíces se han mezclado, y con ellos se han mezclado también las historias buenas que hemos contado sobre la gente de nuestra comunidad.

4. Cuando finalicen todos los grupos, reuniremos el maíz de todas y cada una podrá tomar un poco y llevarlo a casa para sembrarlo o para utilizarlo. Todas somos parte de una comunidad viva, y el maíz mezclado nos ayudará a recordarlo. 


\section{Compartamos nuestras experiencias}

Pregúntale a las niñas cómo nos relacionamos con los niños: ¿̇ienten diferencias de trato? ¿̇Tienen amigos? ¿̇Qué creen que los hace

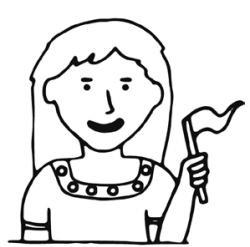
diferentes?

Es importante que las niñas comprendan que los niños no son malos por naturaleza y que hay un sistema violento que nos envuelve a todos. En realidad no hay diferencias pero las ideas violentas hacen que pensemos que debemos tratarnos distinto. Eso es algo que hay que cambiar para que ellos sean más libres y nosotras seamos más felices.

Estrechar lazos de amistad con los niños es bueno. Demuéstrales tus afectos y trata de recordarles que no hay una razón real para tratarnos diferente.

Para poner ejemplos claros cuéntales tus experiencias (buenas o malas) con tus amigos hombres. 


\section{Séptima sesión}

\section{Conozcamos nuestros derechos}

\section{Escuchar es sentir}

Hoy empezaremos nuestra sesión tratando de relajarnos lo más posible. Pídele a las niñas que se paren en un lugar cómodo y que formen un círculo. Diles que cierren los ojos y que respiren profundo. Que se fijen mucho en su respiración. Inhalen juntas lentamente y luego expulsen el aire muy despacio. Tú podrás guiar la respiración. Háganlo durante unos 3 minutos, y traten de mantener los ojos cerrados, muy concentradas.

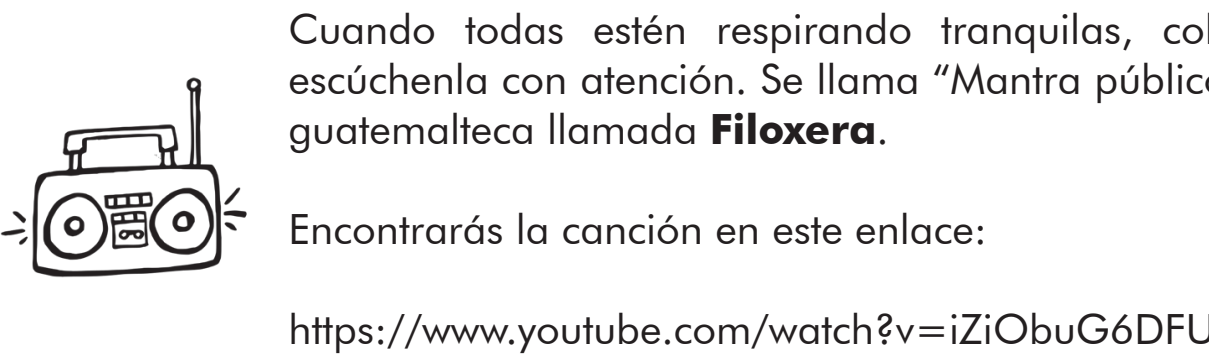

Al terminar, abran los ojos y compartan qué nos hizo sentir. ¿̇Nos tranquilizó? ¿̇Pudimos escuchar su letra? ¿Qué nos llamó la atención?

Reflexiona con ellas sobre estas ideas que nos transmite: Somos una fuerza... Somos energía que fluye... Somos una idea que se comparte...

\section{Aprendamos juntas}

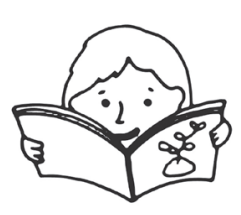

Todos los seres humanos tienen derechos que nadie debe violentar. $Y$ esos derechos han sido reconocidos y protegidos por distintas leyes y compromisos, que garantizan que todas y todos podamos gozar de ellos. Por eso, es importante conocer nuestros derechos, para poder exigir que se cumplan y se respeten.

Realiza una investigación en internet respecto a los principales derechos que aplican para las poblaciones de nuestra comunidad. Utiliza esta clasificación general para ubicar información que puedas trasladar a las niñas:

- ¿Cuáles son nuestros derechos humanos?

- ¿Cuáles son los derechos de las mujeres?

- ¿Cuáles son los derechos de la niñez y la adolescencia?

- ¿Cuáles son los derechos de los pueblos indígenas? 
La respuesta a dichas preguntas se encuentra en el cuerpo legal reconocido por el Estado de Guatemala. Por eso es importante conocer las principales leyes del país, que protegen nuestros derechos fundamentales:

- La Constitución Política de la República

- La Ley contra el femicidio y otras formas de violencia contra la mujer

- La Declaración Universal de los Derechos Humanos

- La Convención sobre los derechos de los niños y las niñas

\section{Compartamos nuestras experiencias}

Por lo general, sabemos muy poco de nuestros derechos y de las leyes que los protegen y garantizan. Por eso, pregúntale a las niñas:

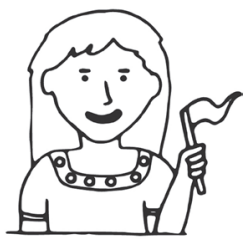

- ¿Qué habían oído respecto a sus derechos?

- ¿̇aben algo de las leyes que les protegen?

- ¿Conocen alguna institución a la cual puedan acercarse si sienten algún riesgo?

Reflexionen juntas sobre sus respuestas, y piensen en una estrategia para fortalecer su capacidad de defender los derechos que les corresponden. Utiliza tus experiencias previas para guiar la conversación.

\section{Hagamos algo juntas}

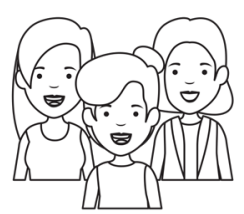

Hoy compartiremos un relato de nuestra propia vida. La idea de esta actividad es que las niñas compartan entre sí una experiencia agradable que hayan tenido, que se cuenten algo bueno que haya pasado a su alrededor, algo que las haya hecho sentir bien.

Para hacerlo, podrán utilizar cualquier recurso: dibujar las escenas de su historia en una hoja de papel, contarla con palabras o dramatizarla. Pídeles que sean lo más creativas posibles y que demuestren su capacidad de recordar lo bueno que les ha pasado y de transmitirlo a las demás.

Dales un tiempo prudencial para que tomen sus decisiones, y cuando estén listas podrán empezar a trabajar. Cuando terminen podrán reunirse en grupos o estar todas juntas para escuchar las historias de cada una. 


\section{Octava sesión}

\section{Abramos otras oportunidades}

Hemos llegado al final de este proceso. Hoy termina un ciclo de ocho semanas que tenía el objetivo de compartir ideas y experiencias para que todas pudiéramos crecer felices. Sin embargo, aquí no termina todo. Cuando un ciclo se cierra, otro comienza de inmediato. $Y$ necesitamos tener claro que el aprendizaje nunca termina. Por eso, hoy queremos responder estas preguntas:

- ¿̇Cómo podemos seguir aprendiendo juntas?

- ¿Qué futuro tendrá la comunidad que aquí hemos formado?

Pongamos en común nuestras ideas, y veamos si somos capaces de armar un plan para seguir creciendo felices.

\section{Aprendamos juntas}

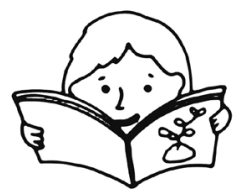

Para esta sesión es importante que las niñas conozcan la experiencia de vida de alguien como tú, que ha sido parte de procesos de formación y que puede convertirse en un referente importante para la vida de las niñas en la comunidad.

Por eso, te sugerimos que para esta actividad invites a alguna amiga cercana que haya sido parte de $\mathrm{AO}$ o que ahora mismo integre Nalebak. Pídele a tu amiga que relate brevemente su experiencia de organización y participación comunitaria. Si no logras que alguien te acompañe, puedes hacerlo tú misma. La idea es que la experiencia de las mujeres de la comunidad se transmita a las niñas.

Cuenten su proceso y respondan todas las preguntas que surjan. Reten a las niñas. Pídanles que piensen en su futuro y en el de su comunidad, y que se fijen metas para buscar una vida digna para todas.

Tu trabajo y el trabajo de tus amigas será un referente importante para la nueva generación de mujeres autónomas, libres y seguras de sí mismas que este grupo de Abriendo Oportunidades ${ }^{\circledR}$ busca formar.

\section{Compartamos nuestras experiencias}

Después de escuchar el relato y la experiencia tuya o de tu amiga, es importante que las niñas se expresen. Para ello, valoremos juntas el camino que hemos recorrido durante estas ocho semanas. Respondamos de viva voz estas preguntas: 


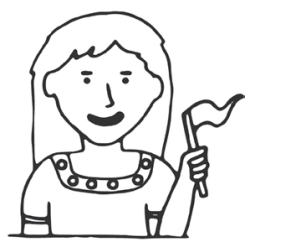

- ¿̇e cumplieron nuestras expectativas?

- ¿Recuerdan qué pensaban antes de venir a la primera sesión?

- ¿Qué ha sido lo más importante que han aprendido durante estas semanas?

Pongan en común sus respuestas y hagan un balance de la experiencia colectiva que han vivido.

\section{Escuchar es sentir}

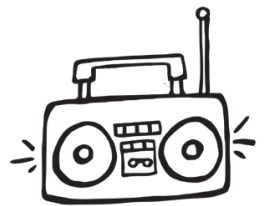

Durante las últimas semanas hemos conocido artistas guatemaltecas que viven intensamente su pasión por la música. ¿̇Alguna vez ustedes se han planteado la posibilidad de ser artistas? Sería emocionante, ¿̇verdad? Hoy conoceremos a una cantante costarricense que vive en Guatemala. Se llama Maf É Tulà, y esta canción lleva por título "Tengo todo". Escuchémosla.

Encontrarás la canción en el siguiente enlace:

https://www.youtube.com/watch?v=anPQufOjsHI

¿̇Les gustó? ¿̇Qué mensaje nos deja?

Preguntémonos, así como la hace ella: ¿̇Qué tenemos para salir adelante?

A manera de reflexión final, pídele a todas las niñas que compartan algo sobre esta pregunta:

- ¿Qué nos deja toda esta experiencia que hemos vivido en las últimas semanas?

\section{Hagamos algo juntas}

La memoria es fundamental para nuestras vidas. En ella vamos acumulando las experiencias buenas, las difíciles, las necesarias para

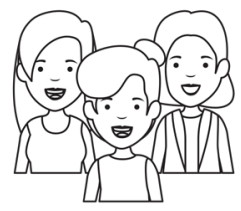
vivir. Por eso, queremos conservar una memoria de estas semanas, y qué mejor que hacerlo con una imagen. Por eso, antes de finalizar la sesión, reúnete con las niñas y tómense una fotografía con algún celular - una cámara que tengan a mano. Esa fotografía marcará un punto importante de su proceso de aprendizaje, que deberá continuar y no detenerse nunca.

De ser posible, imprime la fotografía y que cada una de las niñas conserve una copia. Así podrán revivir los momentos juntas, las ideas y las historias que compartieron. Y cada vez 
que vean la foto recordarán que no están solas, que son parte de una comunidad viva que se preocupa por cada una y que está ahí para ayudar y para ser felices juntas.

Que esta fotografía sea también una promesa para seguir generando puntos de encuentro, para seguir compartiendo historias, experiencias y amistad. 
